\title{
LA CIENCIA Y LA HISTORIA ${ }^{1}$
}

\section{ENRIQUE PEREZ ARBELAEZ}

Eclesiástico; Doctor Summa cum Lade en Ciencias Biológicas de la Universidad REY LUIS MAXIMILIANO, de Munich. Ha sido honrado, entre muchas otras condecoraciones, con la Cruz de Boyacá y, recientemente, con la Medalla "ALEJANDRO DE HUMBOLDT"

\section{EL CASO DE CALDAS-HUMBOLDT}

Al conmemorarse el centenario de la muerte de Alejandro Humboldt, el día 6 de mayo venidero, conviene despejar uno de los hechos del sabio alemán que han dejado más honda huella en la historia científica de Colombia: su negativa a llevar a Francisco José de Caldas, como compañero, en su viaje de Quito hasta Acapulco. Uno y otro personajes nos merecen profundo respeto; Caldas, además de su talento, por su ciencia, por sus hechos y por su martirio, es digno de la veneración de todos los colombianos. Por eso es natural que nos ataña la disensión que se presentó entre estos dos hombres de ciencia, y natural que pretendamos hallarle una explicación. No es cosa fácil, digámoslo de una vez. Pero se sosiega nuestro espíritu al aclarar los hechos y descubrir su raíz en circunstancias que dejan limpio el prestigio científico y humano de estas dos figuras proceras de nuestros albores de pueblo independiente y culto.

No es fácil, decimos, hallar una explicación al caso Caldas-Humboldt. Caldas nos dejó en su correspondencia el más vívido retrato de su alma, generosa y pura, impulsada siempre por anhelos de superación en ciencia, en patria y en servicio, tan excepcionales éstos que no han sido superados en la historia de Colombia; tan diáfano aquel que podemos seguir uno a uno sus sentimientos desde su origen hasta su realización o hasta su frustración y amargo desengaño. Lo que Caldas sintió, las cosas tales, como él las apreció, son un extremo perfectamente reconocible. Desgraciadamente, por fuera de la correspondencia de Caldas, se nos revelan muchos factores históricos que enmiendan sus apreciaciones y nos dejan al descubierto profundas fallas de su criterio y de su carácter. Nadie como Caldas exaltó a Nariño; nadie le hizo acusaciones más acerbas. Nadie como Caldas hizo la apología de los Mutis, de José Celestino y de su sobrino Sinforoso; pero nadie les lanzó improperios con tanta acrimonia. No tuvo Humboldt un panegirista tan fervoroso como Caldas, pero ninguno entre los muchos historiadores que han examinado la vida de Humboldt ha sido tan cruel en interpretar su vida íntima y en empañar su memoria. A estos contrastes se debe restar una condición muy marcada en el estilo

1 La Dirección de la Revista ha cré́do necesario reproducir los dos capítulos que sobre Don Francisco José de Caldas, el Barón de Humboldt y Don Carlos Montúfar, publicó el Padre Pérez Arbeláez en El Tiempo (abril 3 y 23 de 1959, respectivamente), agregando la siguiente nota:

Nunca en la obra literaria, política o científica publicada por Francisco José de Caldas, aparece nada que pudiera lastimar la personalidad de Humboldt. En cambio, dejó varios capítulos destinados a la exaltación de la personalidad o al análisis laudatorio del ilustre científico alemán.

Caldas sufrió injusticias o menosprecios ya reales o imaginarios, y reaccionó humanamente, comunicando confidencialmente, en repulsa inmediata, sin soberbia ni delirio persecutorio, sus cuitas a sus amigos y parientes que le amaban. Así se quejó contra Humboltd, de quien hizo inculpaciones por su conducta que creyó disipada, pero sin sugerir jamás ese estigma sexual del Barón, que ahora se comenta por todas partes, por prurito de algunos de sus biógrafos. Caldas solo llamó, en sus cartas confidenciales, "currutaco" y "adonis" al objeto de las simpatía de Humboldt. Pero currutaco significa elegante con afectación; y adonis, mancebo hermoso, adjetivos que debieron corresponder a la joven personalidad de don Carlos Montúfar, a quien Humboldt pagó su viaje de compañía hasta París, a pesar de que el bello muchacho no le aportaba ninguna colaboración científica. El sabio payanés no hizo sugerencias; apenas dio a sus palabras su valor universal, sin añadir ninguna insinuación malévola.

Esas quejas de Caldas y las citas y comentarios del Padre Pérez Arbeláez serían inofensivos, si no se hubiera querido poner tanta insistencia e intenciones tan discutibles, en las lamentaciones íntimas de nuestro científico, que jamás pensó —modesto y amante platónico de la ciencia como era-, en que algún día su personalidad sería enaltecida entre las grandes figuras proceras, y su vida privada, igual que la pública, entregada a la voracidad de los historiadores y los literatos... Si lo hubiera intuído - buen cristiano como era-, no hubiera dejado jamás rastros de sus resentimientos con nadie, ni menos cierta carta de recriminación a su liviana esposa, ejemplo que sirve para dar valor a nuestra tesis.

El Padre Pérez Arbeláez, científico, escritor y periodista, viene haciendo un porfiado examen de los dos grandes hombres. Así leemos en las notas marginales de la "Historia de las Quinas" de la "Flora de la Real Expedición Botánica del Nuevo Reino de Granada" (Madrid, 1957), las siguientes palabras escritas por el sabio sacerdote, que copiamos textualmente:

"Dijimos en páginas anteriores que una de las mayores frustraciones de Caldas había sido el rechazo de Humboldt a su comitancia, arrastrado el prusiano por su homosexualidad...".

Francamente no se sabría decir quien es más pecador: si Oscar Wilde, o quienes aguijoneados por las flaquezas del célebre escritor, construyeron, sin piedad, obras tremendas y deleitables de escándalo...

En todo caso el modesto director de esta Revista, piensa que los hombres no son dioses, y mira con hondo respeto las dos figuras, la de Caldas y la de Humboldt, más brillantes aún por el contraste de sus defectos.

LUIS MARIA MURILLO 
epistolar de aquella época, demasiado meloso y adulador; zalamero y cariñoso por encima de lo que hoy nos parece aceptable. Pero aun reduciendo a su justo valor las apreciaciones favorables de Caldas respecto de las personas contra las cuales se tornó después como enemigo, quedan enormes distancias entre el Caldas favorable y el Caldas vengador. Así aparece que el Caldas todo ternuras, todo sahumerios, todo néctar, cuando se le truncaba la ilusión o se le frustraban las esperanzas, o se le incumplían promesas ciertas o por él imaginadas, se volvía de vino en vinagre, tanto más ácido cuanto que su talento le descubría mejor el lado flaco de sus ídolos del día anterior.

La venida de Humboldt al Nuevo Reino de Granada y a Santa Fe de Bogotá conmovió hasta lo más íntimo a toda la numerosa pléyade de hombres instruídos que en uno $u$ otro grado hacían vida intelectual en Cartagena, Mompox, Honda; en la corte, en Cartago y en Popayán. Si en la porción que hoy es Venezuela, el sabio prusiano halló el apoyo de las autoridades y noble acogida entre las familias más distinguidas; si igual le había de suceder en Quito y en el Perú, en cambio en Santa Fe y en México sus estudios habían de ser colaborados y su conversación había de convertirse en provechosa cátedra para muchos y en estrella orientadora para numerosas vocaciones científicas. El más favorecido por esta luz del meteoro fue Caldas.

Caldas y Humboldt tenían casi la misma edad, nacidos éste en 1769 y el payanés dos años después, en 1771. Llevados por vocación a los mismos estudios, poseídos del mismo fervor naturalista, la vida los había colocado en dos polos opuestos de psicología. Humboldt, aunque no pertenecía a la más rancia nobleza de Berlín, había recibido educación cortesana refinada. Su preparación literaria y científica había sido la mejor que podía impartir Europa, y ella y el carácter de su raza le infundían una gran independencia en su vida, superioridad en su trato y franca libertad en sus modales. Caldas, en cambio, estaba troquelado en Popayán y Santa Fe; su carácter se había formado en el seno de una familia de origen hispánico, bien relacionada pero escasa en bienes de fortuna, y su carrera científica la había hecho él mismo, como quien dice, con las uñas, devorando los libros a su alcance, fabricándose él mismo sus aparatos, devanándose, desentrañándose en vigilias y en observaciones autoformativas. Había un fondo de identidad en Caldas y en Humboldt, pero el uno era todo lo que podía producir Europa y el otro lo más que podía dar de sí la vida criolla. Puestos el uno frente al otro, Caldas era timorato, reconcentrado y se había formado de la vida del científico un concepto austero, polarizado y un tanto monacal.

Cuando Humboldt llegó a Santa Fe, atraído, como él mismo lo comunicó desde La Habana a su hermano Guillermo, por el deseo de ver a Mutis y de estudiar sus colecciones, las preocupaciones de Caldas lo llevaban lejos de sus estudios científicos. Sus amigos de la capital le comunicaron la trayectoria del sabio prusiano y su futuro paso por Popayán. Allí estaba Caldas, afectado todavía por el infortunado viaje que había hecho al sur del actual Huila, a La Plata y Timaná, donde pensó vender algunas mercancías: ropas, etc., las cuales perdió porque las mulas en que las llevaba se le rodaron a un abismo, por aquellos andurriales de la cordillera. Pero
Caldas no pudo esperar a Humboldt en Popayán porque un pleito "temerario" sostenido por su familia lo llevaba a Quito. Era un retraso del anhelado encuentro, pero un escenario ideal para efectuarlo, así por la asombrosa naturaleza de Quito como por mantenerse allí todavía vivos los recuerdos de la Expedición Académica de C. de La Condamine, de Don Jorge Juan y Santacilla y de otros, cuyas observaciones ya estaban publicadas y de los cuales Caldas estaba enterado.

La primera noticia del viaje de Humboldt y Bonpland aparece en la correspondencia de Caldas el 20 de mayo de 1801. En sus cartas subsiguientes le sigue con avidez imaginativa a lo largo de su itinerario. Pero mientras Humboldt llegaba a Santa Fe el 5 de julio de 1801 y allí permanecía hasta los primeros días de septiembre, Caldas partía de Popayán para Quito el 11 de agosto de 1801. Humboldt había de recorrer el mismo trayecto, dejando la ciudad del Puracé el 27 de noviembre y llegando a Ibarra el 31 de diciembre. Allí habría salido Caldas a encontrarle. Fue como un amanecer en el espíritu del neogranadino.

El tener preparado algo que llamara la atención de Humboldt, se convirtió en suprema aspiración para Caldas. Creyendo que era una novedad científica, miró por perfeccionar y comprobar hasta los ápices su método de medir las alturas sobre el mar, por las temperaturas de ebullición del agua destilada; en Popayán dejó, para que su amigo Arboleda la enseñara a Humboldt, una relación de sus mejores observaciones y los mapas, levantados por él, desde Tocaima a Timaná. Su emoción fue inconmensurable al ver el óptimo aprecio que aquellos trabajos producían en el ánimo del científico viajero. Era todo ello apenas natural. Pero Caldas recuerda que La Condamine había sido acompañado por dos españoles, Juan y Ulloa, quienes de tal viaje habían salido para la Academia y hacia los mayores honores. Quiere en su favor éxitos parecidos y se despierta en él un anhelo irresistible de acompañar a Humboldt en su viaje hasta México. Así se lo expresa, y recibe de él una respuesta evasiva. Si el señor Mutis lo propone, Caldas será compañero de Humboldt. Eso bastó para que Caldas moviera cielo y tierra, con Mutis, con Don Ignacio de Pombo, con los amigos payaneses de Bogotá, hasta con el mismo Virrey, para que se le facilitara su viaje. Llegó la nota de Mutis a pedir de boca, y no solamente la solicitud para que Humboldt llevara consigo a Caldas, sino, lo que sólo se podía esperar de un ánimo tan generoso, tan americanista, tan activo en el adelanto científico del Nuevo Reino: el giro en dinero que cubría los gastos del viaje de Caldas. Día de tremenda conmoción para éste. Humboldt niega haber recibido noticias de Mutis, después dice que sí las posee pero que ha resuelto viajar solo. El desengaño de Caldas es ilímite. Se compara con el prusiano y lo halla inferior a su prestigio, bajo el punto de vista humano; falaz, ligero de cascos, inseguro en las observaciones. Quien la víspera era el ídolo, el dechado, el mayor científico del mundo.

Parece que Quito era, por entonces, una ciudad bastante libre, y que Humboldt cedió a la geopsique de su molicie. Jóvenes libertinos se introdujeron al trato del sabio y alternaban en sus ocupaciones los estudios botánicos, los ascensos a los nevados, las visitas a los monumentos que testificaban la obra de otros sabios, y las 
diversiones. A Caldas eso le parecía desconcertante. Para remate, Humboldt, por su lado, elige para acompañarle a un joven que según las frases de Caldas es "ignorante sin principios y disipado", "un joven currutaco". Caldas cierra sus cartas de loas, de entusiasmo, de dolor, de resentimiento, con esta frase tormentosa escrita el 21 de junio de 1802: "El señor Barón de Humboldt partió de aquí el 8 del corriente con Mr. Bonpland y su Adonis que no le estorba para viajar, como Caldas".

Si estas últimas palabras del payanés se compulsan con ciertas apreciaciones de los modernos biógrafos de Humboldt que las profieren como taponazo de descubridores freudianos, llegaremos a la conclusión de que el sabio prusiano padecía desviaciones psicológicas ambiguas. Sin embargo, las mismas descripciones hechas por Caldas de la conducta de Humboldt en Quito, aunque arguyen su disipación momentánea, no se salen de lo normal psicológico y subconsciente. En el fondo, lo que padecía Humboldt venía de su infancia, de la conducta sobreprotectora de su madre la Baronesa, de la severidad con que ésta reprimió todas sus expansiones y de la perenne postposición a su hermano a que ella lo sometió. Era, en parte, una misoginia.

Caldas era también un continuo censor y un rígido testigo, y Humboldt no quiso continuar en América aquello de que venía huyendo desde Alemania. Sólo que los freudianos creen dar en el clavo cuando más y mayores abismos descubren en los genios.

Ahora, siglo y medio después de los sucesos, cabe preguntar qué hubiera sido de Caldas si Humboldt lo hubiera tomado como un discípulo a su lado, él que con unos días de su trato dio un vuelco a su vida y se convirtió en el más exacto informador de Humboldt, como éste mismo, en muchos pasajes de sus obras, lo reconoce. $\mathrm{Y}$ también, qué gloria hubiera ganado Humboldt si, no obedeciendo a impulsos del subconsciente, deja en suelo americano, un americano tan valioso en ciencia y en servicio como, con su sangre, lo comprobó Francisco José de Caldas.

\section{NO HUBO TAL ADONIS}

Lo que dijimos hace pocos días sobre las relaciones Caldas-Humboldt, pide algún complemento; porque aunque el rechazo del sabio prusiano a la compañía de Caldas, para su vuelta Quito-Callao-Guayaquil y México fue interpretado por Caldas de la manera más aviesa: "se fue el Barón con su Adonis", muchos datos históricos nos inducen a aceptar explicaciones más mitigadas, más normales y ventilables.

El que llama Caldas "joven currutaco", "ignorante, sin principios y disipado", era Carlos Montúfar, hijo de don Juan Pío Aguirre y Montúfar, Marqués de Selva Alegre, en cuya casa y con cuya familia estaban viviendo Humboldt, Bonpland y el mismo Caldas.

En esa casa o, más bien, finca de campo en Chillo, por primera vez durante su viaje americano, Humboldt, educado en un medio aristocrático, se sintió entre sus iguales y debió recordar el castillo de sus padres en Tegel y ese ambiente refinado, abastecido, de caballerizas y de palafrenes, de arbolados y huertos cuidadosamente mantenidos, de lacayos y espoliques, que en aquellos tiempos era privilegio de las gentes de alcurnia. Es sintomático lo que refieren los biógrafos. Del fondo de los baúles de Humboldt salieron a lucir los trajes de fantasía, chaquetilla azul con solapas amarillas, llamativos botones y charreteras, chaleco blanco, ceñidos calzones y botas hasta las rodillas. Wolfgang von Hagen en "South American Called Them", trae un retrato de Humboldt pintado en Quito por un "native" donde se lo ve en ese traje juvenil y con un peinado y un tupé que envidiarían las damas de nuestro tiempo. Doña Rosita, hija también del Marqués, refiere, sin embargo, que el prusiano encantador, no se sentaba a la mesa más largo de lo preciso para satisfacer el hambre y hacer sus cumplimientos a las damas, sino que luego salía al campo a recoger plantas y rocas o a examinar bajo el cielo abierto las estrellas de la noche. En esas diarias y cortas salidas, el compañero habitual de Humboldt era Carlos Montúfar, muchacho despierto, alegre y con sentido de aventura.

Todo esto, que nos parece tan natural, fue lo que mereció tan acres censuras de Caldas. Es verdad que Carlos Montúfar era solo un joven inmaturo sin ningún interés ni conocimiento científico, pero era el hijo de los nobles dueños de casa, alerta a que los huéspedes estuvieran bien servidos; dotado de buen trato y humor, con que supo cautivar la simpatía de Humboldt. Había que reconocerle, además, valor en los peligros. En la arriesgada subida al Chimborazo, en que no pudieron llegar a la cima, pero sí a 5.800 metros, la mayor altura escalada hasta entonces por el hombre, todos los del grupo sufrieron las consecuencias de la soroche, vómitos, desvanecimientos, sangre en las encías y en la conjuntivas. Carlos manaba sangre por ojos y oídos; pero no echó pie atrás hasta perder el conocimiento y hubo de ser bajado en hombros. Aquel episodio no se había de borrar jamás de la memoria de Humboldt como signo de sus costumbres de resolución y de hombría.

Humboldt fue muy claro con Caldas al expresarle los motivos para no llevarlo consigo. Su rostro era severo y triste; su conducta parsimoniosa y reprensiva. Caldas - así lo imaginamos- debía mantener a Humboldt en trance de inteligencia, en aire doctoral, en posición ficticia de autoridad. Y eso, para cualquiera, sabio o no, es intolerable a la larga. Además - no se debe olvidarel escenario era Quito, la ciudad émulo de Popayán, como se ve claro en la correspondencia del mismo Caldas. A este, sin duda, le repugnaba las etiquetas cortesanas y aristocráticas, al paso que, en la familia Selva- 
Alegre, el payanés modesto y estudioso, sería objeto de muchos reparos, de dimes y diretes que debían llegar a oídos de Humboldt.

La consecuencia de todos estos adjuntos fueron los hechos en que Caldas, la ciencia neogranadina, llevaron las de perder. Carlos Montúfar, en su anonimato científico, acompañó a Humboldt hasta París, pagándole éste su viaje que, por más señas valió 5.000 thalers, unos cuatro mil dólares en nuestra moneda, en tiempo en que el poder adquisitivo del dinero era mucho mayor. Si Caldas perdió, Humboldt también, entre otras cosas porque el viaje de Caldas lo hubiera costeado Mutis.

Humboldt, tras el episodio de Quito, parece que se mostró resentido con Mutis por haber intercedido en favor de Caldas. Pero nunca dejó de rendir homenaje a la sabiduría del criollo a quien había rechazado y afligido. Tampoco Caldas, en sus muchos escritos para el público, dio a conocer su resentimiento, sino solo en sus cartas privadas. Mutis tampoco dio la menor importancia a las quejas del nuevo miembro de su Expedición, por más vestidas de virtud que se le presentaron. Decidió sí, estimular, llamar a su lado y honrar en cuanto pudo a Caldas. Para su propio mal, porque llevó a su casa el más acre crítico de sus cosas y de sus íntimas intenciones.

Si la curiosidad llegara a tanto, pudiéramos seguir la accidentada y trágica historia de Carlos Montúfar a quien Humboldt siempre distinguió con su amistad y quien fue un leal servidor de la libertad de las patrias colombiana y ecuatoriana.

Llegados al puerto de Burdeos el $1^{\text {o }}$ de agosto de 1804, Humboldt, Bompland y Montúfar: el francés se separó para visitar a su familia en La Rochelle. El Barón y el joven ecuatoriano, prosiguieron en coche hasta París. Comenzaba la vida apoteósica de Humboldt que había de girar sobre dos polos: la ciencia y la libertad de los pueblos de América. La primera de estas tendencias se desarrollaría en los Institutos, en los Laboratorios y en los libros; la acción política se movería dentro de la correspondencia, en las noticias, en los conventículos sociales y en acciones diplomáticas.

Carlos Montúfar, si jamás aparece interesado por la actividad intelectual de su gran amigo, quedó envuelto en la empresa de la libertad americana preconizada por él, la cual entonces, penosamente, cautelosamente, si- nuosamente, como el agua llovida en las montañas, comenzaba a abrirse paso, en las mentes de los americanos.

La revolución no nació con un ideario perfectamente configurado ni igual en las cabezas de todos cuantos en ella habían de intervenir. En Santa Fe y en Quito fue su primera tendencia la más españolista, de defender a Fernando VII, víctima del atropello de los franceses. Esta bandera atrajo las mentes, sobre todo de muchos jóvenes hijos de rancias familias españolas, en cuyo caso estaban los Montúfar, Jorge Tadeo Lozano, Nariño, Sinforoso Mutis y el mismo Bolívar. Carlos Montúfar debió regresar a la América en 1810 y desembarcó en Venezuela.

Pronto había de evolucionar la idea de la libertad, como una reacción contra las represiones de Morillo y como una consecuencia de las ideas sembradas, entre otros, por el mismo Humboldt, quien en su frase - con Bolívar y Montúfar en 1804- hacía votos en París por la libertad de los pueblos de América.

Carlos Montúfar actuó en Cartagena y en Bogotá en favor de la independencia y pudo al fin regresar a Quito, donde en 1810, formó la junta de gobierno. No fue muy afortunado en acciones de guerra y enfrentado a Aimerich en la acción de Atar y Vendelama, perdió 90 prisioneros y muchos muertos. Más tarde también, él mismo cayó prisionero. Remitido a España junto con Nariño, se escapó en Panamá, volvió a Bogotá, se unió al ejército de Cabal en el Cauca y sufriendo sus reveses, en la batalla de la Cuchilla del Tambo fue apresado por Warleta, quien lo hizo fusilar en Popayán el 3 de septiembre de 1816. Igual había de ser la suerte de Caldas, pocos días después, el 29 de octubre y en Bogotá, tras algunos hechos que no dicen bien con quién había llamado "Adonis" al hijo del Marqués de Selva Alegre ${ }^{1}$.

Humboldt, en carta a Bolívar, escrita el 19 de julio de 1822, concluye así: "Hago votos por vuestro bienestar, por la prosperidad de la libertad de un continente que miro como mi segunda patria. Las cenizas de nuestro desgraciado amigo, Carlos Montúfar, reposan sobre el territorio de la república. No serán jamás olvidadas por aquel que hace honor al valer infortunado".

1 Sobre la personalidad de Caldas puede leerse, con provecho, el capítulo "El Amor y la Sabiduría de Caldas" de Luis María Murillo, de la obra "Francisco José de Caldas", editada como suplemento de la "Revista de la Academia". (Nota de la Dirección). 